\title{
A Study on the Impact of Artificial Intelligence Industry on Macroeconomy: Evidence from United States of America
}

\author{
Yugang $\mathrm{He}^{*}$
}

Received: September 16, 2018. Revised: September 28, 2018. Accepted: October 05, 2018.

\begin{abstract}
Purpose - The artificial intelligence industry plays an increasingly significant role in stimulating the development of United States of America's economy. On account of this background, this paper attempts to explore the impact of artificial intelligence industry on United States of America's macroeconomy.

Research design, data, and methodology - This paper mainly focuses on the impact of artificial intelligence industry on GDP, employment, real income, import, export and foreign direct investment. Furthermore, the Phillips-Perron test and Canonical cointegrating regression will be employed to examine the impact of artificial intelligence industry on United States of America's macroeconomy with a sample form 2010-Q1 to 2017-Q4.

Results - Via the empirical analysis, the results reveal that the artificial intelligence industry has a positive effect on United States of America's GDP, employment, real income, export and foreign direct investment. Conversely, the artificial intelligence industry has a negative effect on United States of America's import.

Conclusions - In summary, the impact of artificial intelligence industry on United States of America's macroeconomy is positive and significant in statistics. Therefore, the government of United States of America should put more input into artificial intelligence industry.
\end{abstract}

Keywords: Artificial Intelligence Industry, United States of America's Macroeconomy, Canonical Cointegrating Regression.

JEL Classifications: C13, E27, L69.

\section{Introduction}

Artificial intelligence, sometimes called machine intelligence, is intelligence demonstrated by machines, in contrast to the natural intelligence displayed by humans and other animals. It is an area of computer science that emphasizes the creation of intelligent machines that work and react like humans. Some of the activities computers with artificial intelligence are designed for speech recognition, learning, planning and problem solving. The emerging of it has not only changed individual's lifestyle, but also brought the current world into a new era. With the progress of the times, the artificial intelligence is becoming more and more important to mankind. Owing to this reason, a large number of scholars have started to pay attention to its impact on our society, especially in economics. For example, Lankisch (2017) analyzes the relationship between artificial intelligence

* First Author, Doctoral Student, Department of International Trade, Chonbuk National University, South Korea.

E-mail: 1293647581@jbnu.ac.kr. and wage inequality. And Virgillito (2017) also studies the impact of artificial intelligence on employment. Meanwhile, Goldfarb and Trefler (2017) explore the impact of artificial intelligence on trade.

In this paper, we set the United States of America as an example to exploit the impact of artificial intelligence industry on macroeconomy. There into, the input of artificial intelligence industry will be treated as an economic variable. In order to analyze its importance to United States of America's macroeconomy, the quarterly data sets form 2010-Q1 to 2017-Q4 are employed to run an empirical analysis under the Canonical cointegrating regression (CCR). In this paper, we mainly focus on the impact of artificial intelligence industry on United States of America's GDP, employment, real income, import, export and foreign direct investment. Furthermore, a menu of statistic approaches such as Phillips - Perron test and Canonical cointegrating regression will be employed to examine the impact of artificial intelligence industry on United States of America's macroeconomy. Via the Canonical cointegrating regression 
analysis, the results report that the artificial intelligence industry has a positive effect on United States of America's $\mathrm{GDP}$, employment, real income, export and foreign direct investment. Conversely, the artificial intelligence industry has a negative effect on United States of America's import.

To this step, the overall structure of this paper will be formed as following illustrates. Section one provides the introduction. Section two offers the literature review. Section three presents the theoretical framework. Section four reports the empirical analysis. Section five exhibits the conclusion.

\section{Literature Review}

The rapid development of artificial intelligence has made great shocks to the modern macro-economy. The impact of artificial intelligence on macro-economy has become more and more significant. Owing to this background, a large number of scholars employ a great deal of different econometric approaches and samples to exploit how the artificial intelligence impacts the macro-economy. Their achievements will be exhibited as the following shows.

Based on the task based model, Zeira (1998) introduces the automation technology and the number of tasks is assumed to be endogenous. An innovation of the model is to put forward a unified framework. In this framework, tasks previously performed by the workforce can be automated, while new tasks with comparative advantages of the workforce can be created. He finds that the automation has both substitution effects and productivity effects, which reduce the labor demand, while productivity effects increase productivity by replacing labor with cheaper capital and increase demand for labor in tasks that have not yet been automated. Using eight-year stock data from 527 U.S. companies, Brynjolfsson and Hitt (2000) find that computerization has a positive short-term impact on productivity and that it may contribute more to productivity in the long run. Vlieghe, Herbots, and Hanson (2001) attempt to use the neoclassical economic growth model to estimate the economic impact of machine intelligence. The model assumes that machines can complement or replace human labor, and that the possibilities of such complementation or substitution are different in different jobs. Meanwhile, the model assumes that computer technology improves faster than general technology, and that the labor input of machine intelligence can grow rapidly according to needs so that the economic growth rate can be increased by an order of magnitude or more by batch use of machine intelligence. In addition, they point out that this analysis may underestimate the economic impact of machine intelligence because it does not consider the possibility of creating new jobs. However, the research of Acemoglu and Restrepo (2016) makes up for this defects.

Brynjolfsson, Hitt and Kim (2011) use data from 179 large listed companies to study the impact of data and business analysis on firm productivity. They find that firms making decisions based on data and business analysis have higher average productivity. Brynjolfsson and McAfee (2014) believe that the second machine revolution based on the artificial intelligence and digital revolution will achieve unprecedented technological progress. The artificial intelligence is regarded as a new factor of production. They point out that the artificial intelligence will promote the economic growth at least three ways. First, the artificial intelligence can automate complex physical tasks, an effect known as "intelligent automation." Secondly, the artificial intelligence can supplement existing labor and assets, enhance worker's ability and capital efficiency. Third, the artificial intelligence can promote innovation and spread to various industries. Brynjolfsson, McAfee and Spence (2014) suggest that the possible source of increased income inequality caused by artificial intelligence is the imbalance in capital returns. They find that machines could replace more types of labor, creating more capital because they can replicate themselves.

David (2015) points out that if automation will make part of the workforce redundant, the main economic problem would be distribution, not scarcity. Berg, Buffie and Zanna (2016) propose that the replacement of unskilled labor by robots in developing countries will reduce the relative wages of these countries, thereby affecting the distribution of international output. Berger and Frey (2016) find that rising income inequality among different classes of people also leads to increased regional inequality and the gathering of highly skilled workers in cities that create new jobs, which are often inconsistent with cities that suffer from job losses or substitutions, so income inequality between cities will gradually increase. DeCanio (2016) employs the Houthakker model, which includes labor, machinery and ordinary capital, is used to analyze the effect of the wide application of artificial intelligence on wages. His findings show that the effect depends on the form of total production relationship and the substitution relationship between human and machine labor. Future advances in artificial intelligence may reduce wages and increase inequality, unless the return on robotic capital is widely distributed among the population, but how that will happen is unclear.

Acemoglu and Restrepo (2017) consider that the artificial intelligence will promote the productivity and economic growth, but some scholars worry that artificial intelligence may bring about unemployment of low-and middle-skilled workers and increase the negative impact of income inequality. If we can't find a way to create common prosperity, the adoption and development of artificial intelligence technology may slow down or even stop for political reasons. Guerreiro, Rebelo, and Teles (2017) point out that when the economy is fully automated, it is not appropriate to levy taxes on robots. Because workers will no longer have to work after the economy is fully automated, taxing robots will distort production decisions and will not reduce income inequality. Using data from EUKLEMS, 
Thomas (2017) finds that investment in information and communication technology (ICT) will boost employment. Using a 15-year dynamic panel patent data set from 15 countries and 8 departments in the OECD, Hoedemakers (2017) assesses the impact of advances in robotics on the labor market using the GMM method and finds that advances in robotics have a moderately positive impact on employment. Acemoglu and Restrepo (2017) analyze the impact of increased use of robots on the local labor market in the United States between 1990 and 2007. Their results show that the use of robots will indeed reduce employment, with an increase in robots per 1,000 people, resulting in a reduction of about 0.18 to 0.34 percent of the workforce. However, using German IFR data from 1994 to 2014, David (2017) finds that robotic use does not cause overall job losses, but only changes the composition of German employment, namely, robotic use will reduce manufacturing employment, but increase employment in the service sector. Acemoglu and Restrepo (2018) point out that factors that might limit productivity gains include the inadaptability of skills required for new technologies to the skills provided by the workforce, and the introduction of automation at an excessive rate. New tasks tend to use new skills, but if the education system does not provide them in a timely manner, economic transformation will be hampered. In addition, because the current tax system tends to subsidize capital rather than labor, and labor market friction and imperfection, balanced wages will be higher than labor social opportunity costs, resulting in the over-use of automation technology, capital and labor misallocation, hindering the promotion of labor productivity.

In summary, the previous researches cited in this paper mainly focus on the impact of artificial intelligence on one part of economy such as productivity, economic growth, employment and income inequality. In order to make a difference with others, this paper sets the United States of America as an example to explore the impact of artificial intelligence on macroeconomy (GDP, employment, real income, import, export and foreign direct investment). this point is also the biggest innovation of this paper.

\section{Theoretical Framework}

\subsection{Modeling}

The artificial intelligence industry belongs to emerging industry, also, called sunrise industry. Recently, the explosive development of artificial intelligence industry has attracted a mass of experts and scholars' interests to explore it. From a entirely new angle, this paper will attempt to unearth the impact of artificial intelligence industry on United States of America's macroeconomics. Due to that there are a great deal of indexes to measure the development of macroeconomy, this paper will pick out some well-understood and representative macroeconomics variables (real GDP, employment figure, real income, import, export and foreign direct investment) of United States of America to tap how the artificial intelligence industry affect the United States of America's macroeconomy. Based on that there are only few empirical references about this proposition, this paper will take the linear econometric approach (Canonical Cointegrating Regression) to study the impact of artificial intelligence industry on United States of America's macroeconomy for the sake of accuracy.

The linear model with a dependent variable (real GDP) gives:

$$
\begin{aligned}
& \log G D P_{t}=C_{1}+\alpha_{1} \log A I_{t}+\beta_{1} \log E M P_{t}+\gamma_{1} \log I N C_{t}+\delta_{1} \log I M_{t} \\
& +\sigma_{1} \log E X_{t}+\rho_{1} \log F D I_{t}+\varepsilon_{1 t}
\end{aligned}
$$

The linear model with a dependent variable (employment figure) gives:

$$
\begin{aligned}
& \log E M P_{t}=C_{2}+\alpha_{2} \log A I_{t}+\beta_{2} \log G D P_{t}+\gamma_{2} \log I N C_{t}+\delta_{2} \log I M_{t} \\
& +\sigma_{2} \log E X_{t}+\rho_{2} \log F D I_{t}+\varepsilon_{2 t}
\end{aligned}
$$

The linear model with a dependent variable (real income) gives:

$$
\begin{aligned}
& \log I N C_{t}=C_{3}+\alpha_{3} \log A I_{t}+\beta_{3} \log G D P_{t}+\gamma_{3} \log E M P_{t}+\delta_{3} \log I M_{t} \\
& +\sigma_{3} \log E X_{t}+\rho_{3} \log F D I_{t}+\varepsilon_{3 t}
\end{aligned}
$$

The linear model with a dependent variable (import) gives:

$$
\begin{aligned}
& \log I M_{t}=C_{4}+\alpha_{4} \log A I_{t}+\beta_{4} \log G D P_{t}+\gamma_{4} \log E M P_{t}+\delta_{4} \log I N C_{t} \\
& +\sigma_{4} \log E X_{t}+\rho_{4} \log F D I_{t}+\varepsilon_{4 t}
\end{aligned}
$$

The linear model with a dependent variable (export) gives:

$$
\begin{aligned}
& \log E X_{t}=C_{5}+\alpha_{5} \log A I_{t}+\beta_{5} \log G D P_{t}+\gamma_{5} \log E M P_{t}+\delta_{5} \log I M_{t} \\
& +\sigma_{5} \log I N C_{t}+\rho_{5} \log F D I_{t}+\varepsilon_{5 t}
\end{aligned}
$$

The linear model with a dependent variable (foreign direct investment) gives:

$$
\begin{aligned}
& \log F D I_{t}=C_{6}+\alpha_{6} \log A I_{t}+\beta_{6} \log G D P_{t}+\gamma_{6} \log E M P_{t}+\delta_{6} \log I M_{t} \\
& +\sigma_{6} \log I N C_{t}+\rho_{6} \log E X_{t}+\varepsilon_{6 t}
\end{aligned}
$$

From equation (1) to equation (6), GDP stands for the real gross domestic products; $E M P$ stands for the employment figure; INC stands for the real income; IM stands for the total import; $E X$ stands for the total export; FDI stands for the actual utilization of foreign direct investment; $C$ stands for the constant; $\varepsilon$ stands for the error term; $\alpha, \beta, \delta, \gamma, \sigma, \rho$ are the coefficients of variables, respectively.

According to the value of $\alpha$, it can be known how the artificial intelligence industry affects these variables (real GDP, employment figure, real income, import, export and foreign direct investment), namely, United States of America's macroeconomy. Specifically speaking, if $\alpha>0$, the 
artificial intelligence industry has a positive effect on United States of America's macroeconomy; if $\alpha<0$, the artificial intelligence industry has a negative effect on United States of America's macroeconomy; if $\alpha=0$, the artificial intelligence industry has no effect on United States of America's macroeconomy.

\subsection{Assumption Analysis}

In the light of existing economic theories and achievements of previous studies, the theoretical assumptions about the impact of artificial intelligence industry on macroeconomy can be conducted. On account of these assumptions, a large number of econometric approaches will be used to verify whether these assumptions work or not.

These assumptions will be listed as the following shown.

Assumption one (GDP):

Artificial intelligence is a major innovation in science and technology field. A general view of the existing literature is that the artificial intelligence can promote economic growth via increasing the productivity. Therefore, the artificial intelligence industry has a positive effect on economic growth.

Assumption two (employment):

The development of artificial intelligence will lead to the gradual reduction of the cost of automation, which will lead to the substitution of machines for human labor. Therefore, the artificial intelligence industry has a negative effect on employment.

Assumption three (real income):

The artificial intelligence has greatly increased the productivity. Due to this, the output has also increased significantly, which will lead to an increase in the per capita GDP. Apart from taxes, the real incomes will also increase. Therefore, the artificial intelligence industry has a positive effect on real income.

Assumption four (export):

The artificial intelligence has led to mass production. According to market supply and demand, the average price level will drop. However, the foreign average price level will keep unchanged. Due to the price difference home and abroad, the export will increase. Therefore, the artificial intelligence industry has a positive effect on export.

Assumption five (import):

The artificial intelligence has led to mass production. According to market supply and demand, the average price level will drop. However, the foreign average price level will keep unchanged. Due to the price difference home and abroad, the import will decrease. Therefore, the artificial intelligence industry has a negative effect on import.
Assumption six (foreign direct investment):

Due to the extensive application of artificial intelligence, the investment cost will be greatly reduced and the work efficiency will be greatly improved. Because of that the profits of foreign enterprises will be increased significantly, which will attract a large number of foreign enterprises to invest in home country. Therefore, the artificial intelligence industry has a positive effect on foreign direct investment.

\section{Empirical Analysis}

\subsection{Stationarity Test}

As well known, a portion of macroeconomic variables are not stationary. If these non-stationary macroeconomic variables are directly to perform an empirical regression, the estimated values may be biased and inconsistent. We often regard this phenomenon as the spurious regression. Currently, there a mass of approaches to test the stationarity of macroeconomic variables. Usually, we employ the Augmented Dicky-Fuller (ADF) Test and the Phillips-Perron (PP) test to test the stationarity of macroeconomic variables. In this paper, the Phillips-Perron (PP) test will be used to test the stationarity of macroeconomic variables used to perform an empirical regression. Before testing the stationarity of macroeconomic variables, these macroeconomic variables will be processed by taking them into logarithm. The purpose is to remove the special points and the heterosedasticity. The results of Phillips-Perron test show in <Table 1$\rangle$.

<Table 1> Results of Phillips-Perron Test

\begin{tabular}{|c|c|c|c|c|c|}
\hline \multirow{2}{*}{ Variable } & \multirow{2}{*}{$\begin{array}{c}\text { Adj. } \\
\text { t-Stat }\end{array}$} & \multicolumn{3}{|c|}{ Test critical values } & \multirow{2}{*}{ Prob.* } \\
\cline { 3 - 5 } & $\mathbf{1 \%}$ level & $\mathbf{5 \%}$ level & $\mathbf{1 0 \%}$ level & \\
\hline $\log A I$ & -0.843 & -3.662 & -2.960 & -2.619 & 0.793 \\
\hline $\log E M P$ & -1.387 & -3.662 & -2.960 & -2.619 & 0.615 \\
\hline $\log E X$ & -1.596 & -3.662 & -2.960 & -2.619 & 0.519 \\
\hline $\log F D I$ & -1.605 & -3.662 & -2.960 & -2.619 & 0.468 \\
\hline $\log G D P$ & -1.829 & -3.662 & -2.960 & -2.619 & 0.412 \\
\hline $\log I M$ & -0.918 & -3.662 & -2.960 & -2.619 & 0.772 \\
\hline $\log I N C$ & -1.228 & -3.662 & -2.960 & -2.619 & 0.373 \\
\hline$\Delta \log A I$ & -3.093 & -3.670 & -2.964 & -2.621 & 0.038 \\
\hline$\Delta \log E M P$ & -3.689 & -3.670 & -2.964 & -2.621 & 0.010 \\
\hline$\Delta \log E X$ & -7.822 & -3.670 & -2.964 & -2.621 & 0.000 \\
\hline$\Delta \log F D I$ & -6.775 & -3.670 & -2.964 & -2.621 & 0.000 \\
\hline$\Delta \log G D P$ & -5.914 & -3.670 & -2.964 & -2.621 & 0.000 \\
\hline$\Delta \log I M$ & -8.619 & -3.670 & -2.964 & -2.621 & 0.000 \\
\hline$\Delta \log I N C$ & -5.904 & -3.670 & -2.964 & -2.621 & 0.000 \\
\hline
\end{tabular}

Note: *MacKinnon (1996) one-sided p-values. $\wedge$ denotes the first difference.

The principle of Phillips - Perron test is that assume that the variable has a unit root, also, called the null hypothesis. If the variable has a unit root, it means that the variable is non-stationary. While if the variable does not has a unit root, it means that the variable is stationary. <Table 1> exhibits the results of Phillips - Perron test. We can find 
that the null hypotheses (all variables have a unit root) are accepted. Said differently, all variables are non-stationary at their own levels. However, if all variables are taken by the first difference, the null hypotheses (all variables have a unit root) are rejected at $5 \%$ significant level. Namely, all of them have become stationary at $5 \%$ significant level. Therefore, these stationary variables can used to perform an empirical analysis.

\subsection{Canonical Cointegrating Regression}

The cointegration equation must be estimated after there is cointegration relationship among the tested variables. The most commonly used cointegration estimation method is the ordinary least squares. However, if the explanatory variable is endogenous or the regression error term is sequentially correlated, the parameters estimated by the ordinary least squares are biased (Second order bias consists of endogenous and non-central bias). To solve the problem caused by the ordinary least squares parameter estimation, Phillips and Hansen (1990) modify the ordinary least squares' estimator by the non-parametric method, which is called fully modified ordinary least squares. Phillips (1995), Kitamura and Phillips (1997) further expand to the fully modified ordinary least squares. Park (1992) proposes the Canonical cointegrating regression, called typically correlative cointegration. This method is similar to the fully modified

<Table 2> Results of Canonical Cointegrating Regression

\begin{tabular}{|c|c|c|}
\hline Equation Order & Dependent Variable & Canonical Cointegrating Equation \\
\hline $\begin{array}{l}\text { Equation } \\
\text { (1) }\end{array}$ & $\log G D P$ & 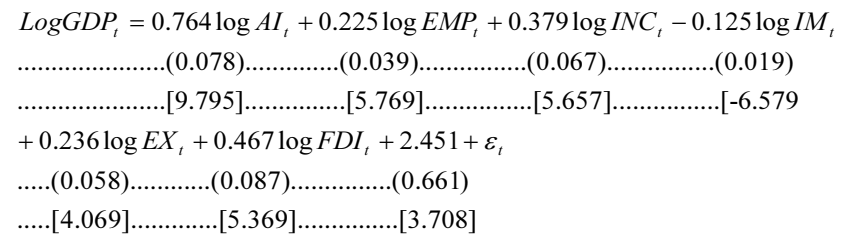 \\
\hline $\begin{array}{l}\text { Equation } \\
\text { (2) }\end{array}$ & $\log E M P$ & 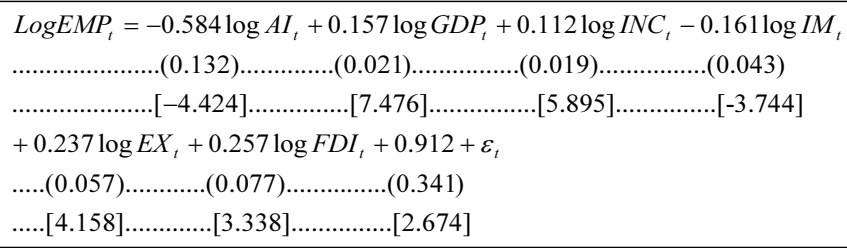 \\
\hline $\begin{array}{l}\text { Equation } \\
\text { (3) }\end{array}$ & $\log I N C$ & 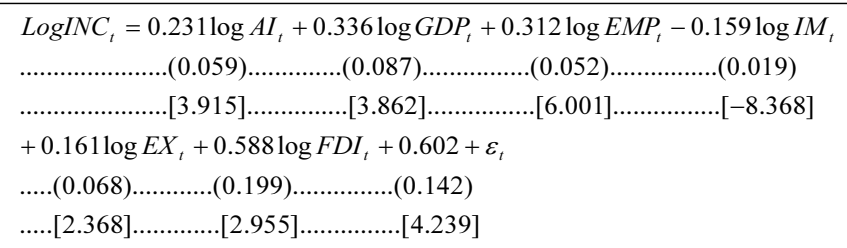 \\
\hline $\begin{array}{c}\text { Equation } \\
\text { (4) }\end{array}$ & $\log I M$ & 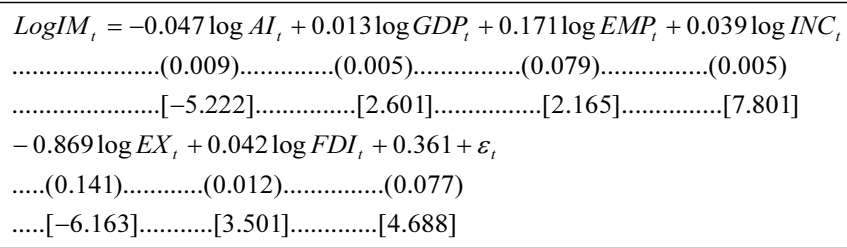 \\
\hline $\begin{array}{l}\text { Equation } \\
\text { (5) }\end{array}$ & $\log E X$ & 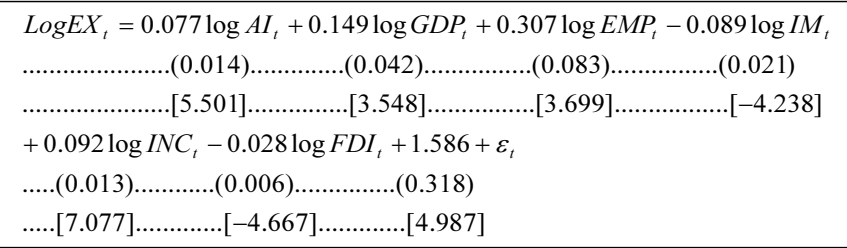 \\
\hline $\begin{array}{c}\text { Equation } \\
\text { (6) }\end{array}$ & $\log F D I$ & 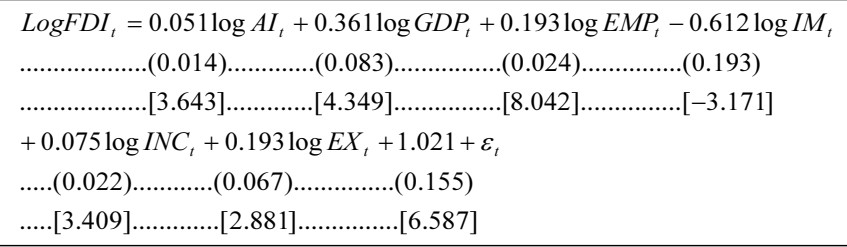 \\
\hline
\end{tabular}

Note: ( ) indicates the standard error. [ ] indicates the value of t-Statistic. 
ordinary least squares in correcting the ordinary least squares' estimators with non-parametric methods, but it eliminates non-central bias by different methods. Phillips and Loretan (1991), Saikkonen (1991), Stock and Waston (2003) modify the parameters of ordinary least squares' estimators by using the lead period and lag period of first-order difference of I (1) variables as explanatory variables. Saikkonen (1991) has proved that the estimators of the fully modified ordinary least squares, the Canonical cointegrating regression and the dynamic ordinary least squares are asymptotically effective estimators. In this paper, the Canonical cointegrating regression will be employed to explore the impact of artificial intelligence industry on macroeconomy from the evidence of United States of America. The empirical results report in $<$ Table 2>.

$<$ Table 2> exhibits the impact of artificial intelligence industry on macroeconomy from the evidence of United States of America.

On equation (1), it explores the impact of artificial intelligence industry on economic growth. As the empirical result shows, the artificial intelligence industry has a positive effect on economic growth. Concretely speaking, $1 \%$ increase in the artificial intelligence industry will lead to $0.764 \%$ increase in the economic growth. Meanwhile, the employment, the real income, the export and the foreign direct investment have a positive effect on economic growth. But the import has a negative effect on economic growth. Specifically, $1 \%$ increase in the employment, the real income, the export and the foreign direct investment will lead to $0.225 \%, 0.379 \%, 0.236 \%$, and $0.467 \%$ increase in the economic growth. And $1 \%$ increase in the import will lead to $0.125 \%$ decrease in the economic growth.

On equation (2), it explores the impact of artificial intelligence industry on employment. As the empirical result shows, the artificial intelligence industry has a negative effect on employment. More specifically, $1 \%$ increase in the artificial intelligence industry will result in $0.584 \%$ decrease in the employment. Simultaneously, the GDP, the real income, the export and the foreign direct investment have a positive effect on employment. However, the import has a negative effect on employment. Specifically, $1 \%$ increase in the GDP, the real income, the export and the foreign direct investment will lead to $0.157 \%, 0.112 \%, 0.237 \%$, and $0.257 \%$ increase in the employment. And $1 \%$ increase in the import will lead to $0.161 \%$ decrease in the employment.

On equation (3), it explores the impact of artificial intelligence industry on real income. As the empirical result shows, the artificial intelligence industry has a positive effect on real income. To put it more specifically, $1 \%$ increase in the artificial intelligence industry will result in $0.231 \%$ increase in the real income. Simultaneously, the GDP, the employment, the export and the foreign direct investment have a positive effect on real income. However, the import has a negative effect on real income. Specifically, $1 \%$ increase in the GDP, the employment, the export and the foreign direct investment will lead to $0.336 \%, 0.312 \%$, $0.161 \%$, and $0.588 \%$ increase in the real income. And $1 \%$ increase in the import will lead to $0.159 \%$ decrease in the real income.

On equation (4), it explores the impact of artificial intelligence industry on import. As the empirical result shows, the artificial intelligence industry has a negative effect on import. To be specific, $1 \%$ increase in the artificial intelligence industry will bring about $0.047 \%$ decrease in the import. Simultaneously, the GDP, the employment, the real income and the foreign direct investment have a positive effect on import. However, the import has a negative effect on export. Specifically, $1 \%$ increase in the GDP, the employment, the real income and the foreign direct investment will lead to $0.013 \%, 0.171 \%, 0.039 \%$, and $0.042 \%$ increase in the import. And $1 \%$ increase in the import will lead to $0.869 \%$ decrease in the import.

On equation (5), it explores the impact of artificial intelligence industry on export. As the empirical result shows, the artificial intelligence industry has a positive effect on export. To be specific, $1 \%$ increase in the artificial intelligence industry will bring about $0.077 \%$ increase in the export. Simultaneously, the GDP, the employment and the real income have a positive effect on export. However, the import and the foreign direct investment have a negative effect on export. Specifically, 1\% increase in the GDP, the employment and the real income will lead to $0.149 \%$, $0.307 \%$, and $0.092 \%$ increase in the export. And $1 \%$ increase in the import and the foreign direct investment will lead to $0.089 \%$ and 0.028 decrease in the export.

On equation (6), it explores the impact of artificial intelligence industry on foreign direct investment. As the empirical result shows, the artificial intelligence industry has a positive effect on foreign direct investment. To be specific, $1 \%$ increase in the artificial intelligence industry will bring about $0.051 \%$ increase in the foreign direct investment. Simultaneously, the GDP, the employment, the real income and the export have a positive effect on foreign direct investment. However, the import has a negative effect on foreign direct investment. Specifically, $1 \%$ increase in the GDP, the employment, the real income and the export will lead to $0.361 \%, 0.3193 \%, 0.075 \%$, and 0.193 increase in the foreign direct investment. And $1 \%$ increase in the import will lead to $0.612 \%$ decrease in the foreign direct investment.

Via the Canonical cointegrating regression, we find the cointegrating relationship among these macroeconomic variables of United States of America. In order to ensure the accuracy and unbiasedness of the empirical results, it is very necessary to examine the stability of the residual sequence of equations. The testing results indicate in $<$ Table 3>. 
$<$ Table 3> Stationarity Test of Equations' Rresidual Sequence

\begin{tabular}{|c|c|c|c|c|c|}
\hline \multirow{2}{*}{$\begin{array}{c}\text { Equation } \\
\text { Order }\end{array}$} & \multirow{2}{*}{$\begin{array}{c}\text { Adj. } \\
\text { t-Stat }\end{array}$} & \multicolumn{3}{|c|}{ Test critical values } & \multirow{2}{*}{ Prob.* } \\
\cline { 3 - 5 } & & $\mathbf{1 \% \text { level }}$ & $\mathbf{5 \%}$ level & $\mathbf{1 0 \%}$ level & \\
\hline Equation (1) & -3.344 & -3.670 & -2.964 & -2.621 & 0.022 \\
\hline Equation (2) & -8.140 & -3.670 & -2.964 & -2.621 & 0.000 \\
\hline Equation (3) & -7.156 & -3.670 & -2.964 & -2.621 & 0.000 \\
\hline Equation (4) & -4.065 & -3.670 & -2.964 & -2.621 & 0.004 \\
\hline Equation (5) & -5.934 & -3.670 & -2.964 & -2.621 & 0.000 \\
\hline Equation (6) & -5.920 & -3.670 & -2.964 & -2.621 & 0.000 \\
\hline
\end{tabular}

Note: *MacKinnon (1996) one-sided p-values.

<Table 3> demonstrates stationarity test of equations' residual sequence. From equation (1) to equation (6), we can find that the absolute values of Adj. t-Stat are greater than test absolute critical values at $5 \%$ significant level. It means that all these residual sequences are stationary at their own levels. Said differently, the Canonical cointegrating regression which is conducted in $\langle$ Table 2$\rangle$ is effective and accurate. More importantly, these results also satisfy the assumption analyses in section three.

\section{Conclusion}

The artificial intelligence industry is regarded as an emerging industry, also, called sunrise industry. In recent years, the explosive development of artificial intelligence industry has drawn a huge amount of interest already. From a entirely new angle, this paper will attempt to unearth the impact of artificial intelligence industry on United States of America's macroeconomy. Due to that there are a great deal of indexes to measure the development of macroeconomy, this paper will pick out some well-understood and representative macroeconomics variables (real GDP, employment figure, real income, import, export and foreign direct investment) of United States of America to tap how the artificial intelligence industry affect the United States of America's macroeconomy. Meanwhile, the quarterly data sets which are sourced from the Organization for Economic Co-operation and Development, the Pitchbook Data and the Economics \& Statistics Administration of United States of America form 2010-Q1 to 2017-Q4 are employed to run an empirical analysis under the Canonical cointegrating regression (CCR). The findings of this paper report that the artificial intelligence industry have a positive effect on United States of America's GDP, employment, real income, export and foreign direct investment. Conversely, the artificial intelligence industry has a negative effect on United States of America's import.

At present, a large number of achievements have been made in the research on the impact of artificial intelligence on United States of America's macroeconomy. However, via the comprehensive literature analysis and the empirical evidence this paper provided, we can also find two critical aspects in the path, mechanism, data and research objects of artificial intelligence. One is that because the artificial intelligence industry is an emerging industry, the mechanism of artificial intelligence is complicated, and it is difficult to be fully introduced into the theoretical model. Actually, the role of artificial intelligence and its impact on United States of America's macroeconomy are much more complicated. The artificial intelligence itself is not only a kind of capital, but also affects the investment of other capital. It may become a new factor of production in the future. Therefore, it is necessary to have a deeper understanding of its mechanism and development to explore the path of artificial intelligence's influence on United States of America's macroeconomy, and exploring how to introduce artificial intelligence into theoretical models will become an important direction for future research. Another is that although the literature has paid wide attention to United States of America's macroeconomic impact of artificial intelligence, the connotation of artificial intelligence is relatively extensive and most of the existing empirical studies focus on a part of artificial intelligence. Therefore, the quantitative research in the existing literature is limited and single. In the future, more empirical data from the world should be used to carry out research to fill the gap between theoretical research and empirical measurement.

All in all, it is an important topic to explore the impact of artificial intelligence on macro-economy. Meanwhile, we need to realize that artificial intelligence technology is still under developing and early spreading stage. There is great uncertainty about the future macroeconomic implications. We expect more and more scholars in the future to strengthen the research on the macroeconomic impact of artificial intelligence, explore how to formulate optimal policies to mitigate the tremendous impact of technological change, ensure that society as a whole enjoys the benefits of artificial intelligence, and help people cope with the opportunities and risks brought about by artificial intelligence correctly. Moreover, the United States of America is regarded as the leader of the artificial intelligence industry in the world. The United States of America's government should share the achievements of the impact of artificial intelligence on macro-economy with the world so as to make full use of artificial intelligence.

\section{References}

Acemoglu, D., \& Restrepo, P. (2017). Secular stagnation? The effect of aging on economic growth in the age of automation. American Economic Review, 107(5), 174-79.

Acemoglu, D., \& Restrepo, P. (2016). The race between machine and man: Implications of technology for 
growth, factor shares and employment (No. w22252). National Bureau of Economic Research.

Acemoglu, D., \& Restrepo, P. (2017). Robots and jobs: Evidence from US labor markets. NBER Working Paper No. 23285.

Acemoglu, D., \& Restrepo, P. (2018). The Race between Man and Machine: Implications of Technology for Growth, Factor Shares and Employment. American Economic Review, 108(6), 1488-1542.

Berg, A., Buffie, E. F., \& Zanna, L. F. (2016). Robots, growth, and inequality. Finance \& Development, 53(3), 10-13.

Brynjolfsson, E., \& Hitt, L. M. (2000). Beyond computation: Information technology, organizational transformation and business performance. Journal of Economic perspectives, 14(4), 23-48.

Brynjolfsson, E., Hitt, L. M., \& Kim, H. H. (2011, April). Strength in numbers: How does data-driven decisionmaking affect firm performance? Social Science Research Network. Retrieved June 23, 2011, from http://ssrn.com/abstract=1819486

Brynjolfsson, E., \& McAfee, A. (2014). The second machine age: Work, progress, and prosperity in a time of brilliant technologies. New York, NY: W. W. Norton \& Company.

Brynjolfsson, E., McAfee, A., \& Spence, M. (2014). New world order: labor, capital, and ideas in the power law economy. Foreign Affairs, 93(4), 44-53.

Berger, T., \& Frey, C. B. (2016). Structural transformation in the OECD: Digitalisation, deindustrialisation and the future of work. OECD Social, Employment, and Migration Working Papers, 193, Retrieved May 22, 2017, from https://www.oxfordmartin.ox.ac.uk/publications /view/2278

David, B. (2017). Computer technology and probable job destructions in Japan: An evaluation. Journal of the Japanese and International Economies, 43, 77-87.

DeCanio, S. J. (2016). Robots and humans-complements or substitutes?. Journal of Macroeconomics, 49, 280-291.

David, H. (2015). Why are there still so many jobs? The history and future of workplace automation. Journal of Economic Perspectives, 29(3), 3-30.

Guerreiro, J., Rebelo, S., \& Teles, P. (2017). Should Robots be Taxed?. Working Papers, .23806, Retrieved May 22, 2017, from http://www.nber.org/papers/w23806.pdf

Goldfarb, A., \& Trefler, D. (2017). A/ and Trade : In Economics of Artificial Intelligence. University of Chicago Press.
Hansen, B. E., \& Phillips, P. C. (1990). Estimation and inference in models of cointegration: A simulation study. Advances in Econometrics, 8(1989), 225-248.

Hoedemakers, L. (2017). The Changing Nature of Employment: How Technological Progress and Robotics Shape the Future of Work. Retrieved May 22, 2017, from https://lup.lub.lu.se/student-papers/search/publication /8916714

Kitamura, Y., \& Phillips, P. C. (1997). Fully modified IV, GIVE and GMM estimation with possibly non-stationary regressors and instruments. Journal of Econometrics, $80(1), 85-123$.

Lankisch, C. (2017). Robots and the skill premium: An automation -based explanation of wage inequality. Hohenheim Discussion Papers in Business, Economics and Social Science, No. 29.

Phillips, A. L. (1995). 1995 Derivatives practices and instruments survey. Financial Management, 24(2), 115-125.

Park, J. Y. (1992). Canonical cointegrating regressions. Econometrica: Journal of the Econometric Society, 60 (1), 119-143.

Phillips, P. C., \& Loretan, M. (1991). Estimating long-run economic equilibria. The Review of Economic Studies, 58(3), 407-436.

Stock, J., Waston, M., Stock, J., \& Watson, M. (2003). Regression with panel data. Introduction to econometrics, 12(1), 123-132.

Saikkonen, P. (1991). Asymptotically efficient estimation of cointegration regressions. Econometric theory, $7(1)$, $1-21$.

Thomas, M. K. (2017). The Rise of Technology and its Influence on Labor Market Outcomes. Gettysburg Economic Review, 101), 3. Retrieved May 22, 2017, from https://cupola.gettysburg.edu/ger/?utm_source=cupola. gettysburg.edu\%2Fger\%2Fvol10\%2Fiss1\%2F3\&utm_medi um=PDF\&utm_campaign=PDFCoverPages

Vlieghe, K., Herbots, K., \& Hanson, K. (2001). Een bronnenboek over kinderrechten: redactionele toelichting bij deel 4: nuttige informatie. In Kinderrechtengids (KIDS): commentaren, regelgeving, rechtspraak, nuttige informatie. Mys \& Breesch.

Virgillito, M. E. (2017). Rise of the robots: Technology and the threat of a jobless future. Labor History, 58(2), 240-242.

Zeira, J. (1998). Workers, machines, and economic growth. The Quarterly Journal of Economics, 113(4), 1091-1117. 